\title{
Shaking Table Tests of Curved Bridge considering Bearing Friction Sliding Isolation
}

\author{
Lei Yan, ${ }^{1}$ Qingning Li, ${ }^{1}$ Chun Han, ${ }^{2}$ and Haotian Jiang ${ }^{1}$ \\ ${ }^{1}$ School of Civil Engineering, Xi'an University of Architecture and Technology, Xian, Shaanxi 710055, China \\ ${ }^{2}$ School of Civil Engineering, Xinxiang University, Xinxiang, Henan 453000, China \\ Correspondence should be addressed to Qingning Li; liqingning1952@163.com
}

Received 27 March 2016; Revised 1 June 2016; Accepted 11 July 2016

Academic Editor: Mahmoud Bayat

Copyright (c) 2016 Lei Yan et al. This is an open access article distributed under the Creative Commons Attribution License, which permits unrestricted use, distribution, and reproduction in any medium, provided the original work is properly cited.

\begin{abstract}
Specific to severe damage to curved bridges in earthquakes caused by the excessive force of the fixed bearings and piers, a new seismic design method on curved bridges considering bearing friction sliding isolation is proposed in this paper. Seismic model bridge and isolation model bridge with similarity ratio of $1 / 20$ were made and the shaking table comparison test was conducted. The experimental results show that the isolation model curved bridge suffered less seismic damage than the seismic model curved bridge. The fundamental frequencies of the seismic model bridge and isolation model bridge decreased and the damping ratio increased with the increase of seismic intensity. Compared with seismic curved bridge, the maximum reduction rates of peak acceleration along the radial and tangential directions on the top of pier of the isolation model curved bridge were $47.3 \%$ and $55.5 \%$, respectively, and the maximum reduction rate of the peak strain on the bottom of pier of the isolation model curved bridge was $43.4 \%$. For the isolation model curved bridge, the maximum reduction rate of peak acceleration on the top of pier was $24.6 \%$ compared with that on the bottom of pier. The study results can provide experimental basis for the seismic design of curved bridges.
\end{abstract}

\section{Introduction}

The frequent earthquake disasters in recent years resulted in severe damage to bridge structures, while the damage to the curved bridges was more serious [1-4]. Compared with the damage form of bridge structures in earthquakes in Northridge, US, and in Hanshin, Japan, the damage form of bridges in China's Wenchuan and Yushu earthquakes mainly presented as girder displacement and girder falling and relatively slight damage to the pier-girder connections and the piers. Upon analysis, laminated rubber bearings were adopted for most bridges and were placed directly on top of the bent cap or abutment in the Wenchuan and Yushu earthquakes, which were the main reasons for such form of damage. The laminated rubber bearings successfully helped avoid or reduce the transfer of seismic inertia force in the earthquakes due to its friction sliding isolation which exhibited favorable static behaviors and excellent seismic performance and thereby rendered the most typical seismic isolation device [57].
Up to date, many scholars have carried out theoretical studies on the application of the isolation device in the highway bridge. Ozbulut and Hurlebaus [8] conducted a sensitivity analysis to examine the effectiveness of an isolation system consisting of shape memory alloy (SMA) device and natural rubber bearing for seismic protection of highway bridges. Zhang et al. [9] proposed a SMA based displacement restraining damping devices to control the seismic response of a fullscale three-dimensional seismically excited highway bridge. The above content mainly relates to the bridge which has complex isolation device. Wang et al. [10] studied the influence of the parameters on the dynamic response of the isolated bridge with lead rubber bearings (LRB). Wilde et al. [11] proposed a very effective passive method, which combined a laminated rubber bearing with a device made of SMA of protecting bridges from the hazard of earthquakes. Bhuiyan and Alam [12] have carried out performance evaluation of multispan continuous highway bridge isolated by an isolation bearing consisting of high damping rubber bearing and $\mathrm{Ni}$ Ti SMA restrainers and demonstrated the effectiveness of the 
bearing in seismic responses of the bridge. A detailed and systematic investigation on the performance of LRB and FPS friction-pendulum system (FPS) isolation systems, provided with supplemental viscous damping under the effect of nearfault ground motions, has been carried out by Providakis [13]. The above content mainly relates to the bridge which has complex isolation device.

In recent years, much progress has been made in the research of isolated curved bridges. Ates and Constantinou $[14,15]$ investigated the seismic behavior of isolated curved bridges in the earthquake including soil-foundation effects, reporting that double concave friction-pendulum bearings offer some advantages for the internal forces on the deck for the considered curved bridge as per the nonisolated curved bridge. In Liu et al.s [16] study on a curved bridge, which considers the effect of bearings friction and viscous dampers, the results show that viscous dampers can reduce the difference of internal force within inner pier of curved bridge, and they can also effectively reduce the bending and twisting coupling effect of curved bridge. Kataria and Jangid [17] found that the use of semiactive variable stiffness damper with different isolators is very effective in controlling the response of the curved bridge. Their results indicated that the curve bridge which considers seismic isolation design can effectively reduce the dynamic response under earthquake action.

The shaking table tests, as an effective means of reappearance of the earthquake process, have been widely adopted at present. On the basis of theoretical research, the scholars have also carried out some shaking table tests on isolated bridges [18-24]. Most of these isolated bridge tests are carried out for the straight bridge, and the shaking table tests for isolated curved bridges are rarely studied. Therefore, the shaking table comparison tests on the two models of curved bridges with or without considering bearings friction sliding isolation were conducted in this paper so as to study the impact of friction sliding of laminated rubber bearings on the seismic performance of the curved bridge.

\section{Shaking Table Test}

2.1. Similarity Relationship. Based on the dynamic test theory $[25,26]$ and in combination with the specific circumstances of the shaking table in the Key Laboratory of Structure Engineering and Earthquake Resistance, Xi'an University of Architecture and Technology, the geometric similarity ratio of the model bridge was determined as $1 / 20$. Other main similarity constants derived from the geometric similarity ratio are shown in Table 1.

2.2. Model Materials. As the model materials used in shaking table tests directly affect the visibility and accuracy of test results, the selection of model materials is very important. HRB335 ribbed bars (nominal yield strength is $335 \mathrm{MPa}$ ) with the diameter of $\Phi 6 \mathrm{~mm}$ were used for the longitudinal reinforcement of model pier and girder; HRB335 plain round bars with the diameter of $\Phi 6 \mathrm{~mm}$ were used for stirrup, with the stirrup spacing being
TABLE 1: Similar constants.

\begin{tabular}{lccc}
\hline Properties & $\begin{array}{c}\text { Physical } \\
\text { quantity }\end{array}$ & $\begin{array}{c}\text { Similitude } \\
\text { relation }\end{array}$ & $\begin{array}{c}\text { Similitude } \\
\text { parameter }\end{array}$ \\
\hline Geometric properties & Length & $S_{l}$ & 0.05 \\
& Strain & $S_{\sigma} / S_{E}$ & 1 \\
Material properties & Stress & $S_{\sigma}=S_{E}$ & 0.6377 \\
& Mass & $S_{\sigma} \cdot S_{l}^{2} / S_{a}$ & $6.377 \times 10^{-4}$ \\
Load & Force & $S_{\sigma} S_{l}^{2}$ & $1.592 \times 10^{-3}$ \\
& Cycle & $S_{l}^{0.5} \cdot S_{a}^{-0.5}$ & 0.1414 \\
Dynamic properties & Acceleration & $S_{a}$ & 2.5 \\
& Gravity & 1 & 1 \\
\hline
\end{tabular}

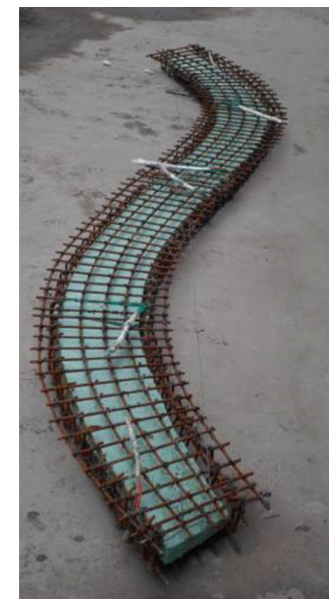

(a) Girder

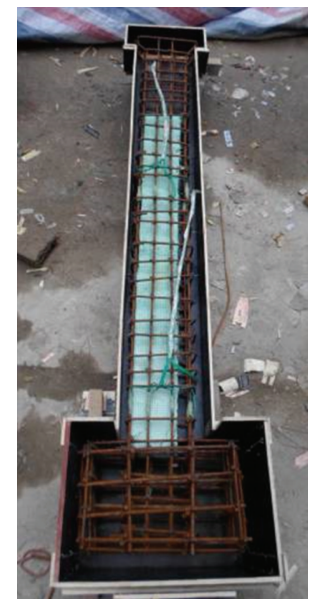

(b) Pier
FIGURE 1: Reinforcement skeleton.

$\Phi 6 \mathrm{~cm}$. The pier-girder reinforcement skeleton is shown in Figure 1. In the model, micro concrete $[27,28]$ was used to simulate the concrete for actual structure, with the mix proportion being water:cement: sand:haydite: stone = $0.435: 1: 1.127: 0.173: 2.72$. The parameter test on micro concrete is shown in Figure 2. Upon test, it is determined that the elastic modulus of micro concrete was $2.2 \times 10^{4} \mathrm{~N} / \mathrm{mm}^{2}$, which satisfies the test requirements.

Two laminated rubber bearings in size of $6 \mathrm{~cm} \times$ $6 \mathrm{~cm} \times 1.5 \mathrm{~cm}$ were installed above each pier in the isolation model. Upon testing, the horizontal shear stiffness of rubber bearings was $k_{x}=k_{y}=2.88 \times 10^{5} \mathrm{~N} / \mathrm{m}$ and vertical stiffness was $k_{z}=5.61 \times 10^{7} \mathrm{~N} / \mathrm{m}$.

2.3. Model Design. In this paper, S-shaped curved bridge is taken as study object and model bridge is designed based on the similarity ratio of $1 / 20$. The model bridge consists of four parts: circular curve, transition curve, transition curve, and circular curve; and the length of each part is $0.933 \mathrm{~m}, 1 \mathrm{~m}, 1 \mathrm{~m}$, and $0.933 \mathrm{~m}$, respectively. The full-bridge span combination is $2 \times 1.785 \mathrm{~m}$; the length of curve is $3.86 \mathrm{~m}$. The superstructure of the model is box girder with uniform cross section and the piers are in rectangular single pier cross section, with the 


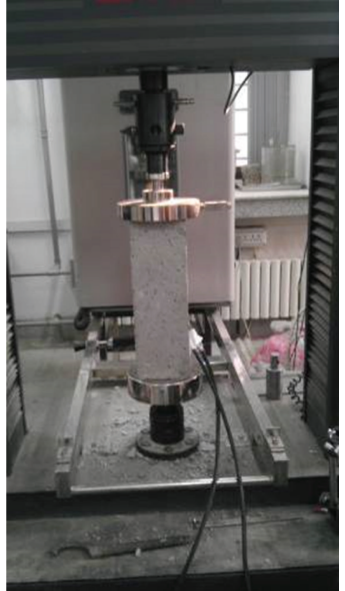

(a) Load

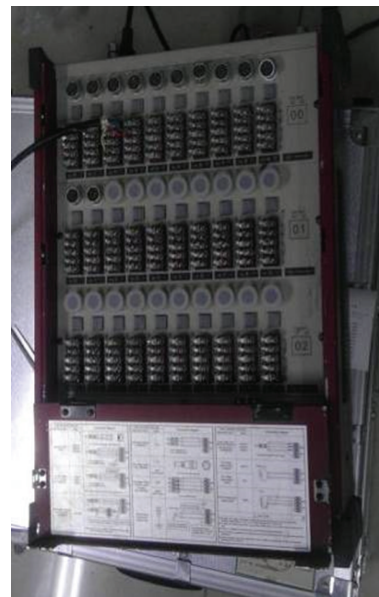

(b) Measurement
FIGURE 2: Loading and measurement of block.

TABLE 2: Correspondences between the prototype and the bridge model.

\begin{tabular}{lcc}
\hline Items & Prototype & Bridge model \\
\hline Span length $(\mathrm{m})$ & 35.7 & 1.785 \\
Curved span length $(\mathrm{m})$ & 38.6 & 1.93 \\
Deck width $(\mathrm{m})$ & 7 & 0.35 \\
Pier height $(\mathrm{m})$ & 31 & 1.55 \\
Girder mass $(\mathrm{kg})$ & 1175737 & 155.3 \\
Pier mass $(\mathrm{kg})$ & 1437012 & 189.6 \\
\hline
\end{tabular}

height of $1.55 \mathrm{~m}$. The correspondences between the prototype and the bridge model are shown in Table 2.

Two curved bridge models are designed based on the parameters shown in Table 2.

Seismic Model. No bearing was set for the model bridge, and it was designed into pier-girder fixed connection.

Isolation Model. Two laminated rubber bearings were set on each pier, and the laminated rubber bearings were placed on the top of the pier directly. The laminated rubber bearings slide along the pier in any direction (Figure 3(d)) in the case of a strong earthquake input.

The main design dimensions and the reinforcement assembly of section of the model bridge are shown in Figures 3 and 4.

2.4. Model Counterweight. The model tests must meet the criterion for dynamical mass similarity. Upon calculation, the total weight of counterweight required was $1321.4 \mathrm{~kg}$ and the actual weight of counterweight was $1040 \mathrm{~kg}$. The counterweight rate could be up to $80 \%$, so the requirements of shaking table test were satisfied. The two models applied with the counterweight are shown in Figure 5.

2.5. Layout of Measuring Points. In this test, the layouts of measuring point of the two models were the same. Nine
TABLE 3: Load conditions.

\begin{tabular}{lccc}
\hline $\begin{array}{l}\text { Load } \\
\text { condition }\end{array}$ & Model & $\begin{array}{c}\text { The inputted peaks } \\
\text { acceleration of } \\
\text { shaking table }(\mathrm{g})\end{array}$ & $\begin{array}{c}\text { The measured } \\
\text { peaks acceleration } \\
\text { of shaking table }(\mathrm{g})\end{array}$ \\
\hline 1 & 0.250 & 0.246 \\
2 & Seismic & 0.375 & 0.346 \\
3 & model & 0.500 & 0.486 \\
4 & & 0.750 & 0.736 \\
5 & & 1.000 & 0.973 \\
\hline 6 & & 0.250 & 0.237 \\
7 & Isolation & 0.375 & 0.335 \\
8 & model & 0.500 & 0.472 \\
9 & & 0.750 & 0.717 \\
10 & & 1.000 & 0.998 \\
\hline
\end{tabular}

acceleration sensors measuring points were arranged on the top of shaking table, the tangential direction of the top and bottom of piers $\# 1, \# 2$, and $\# 3$, and the radial direction of the bottom and top of pier \#3, respectively. Four displacement sensors were arranged in the radial and tangential direction at the top of pier \#2 and the girder (bridge deck), respectively. 12 strain gauges were arranged on steel bar at the bottom of the piers.

The PCB type series 380 GFB3G/30AY acceleration sensors were used to measure acceleration response of the models. 891-II type displacement sensors were used to measure the displacement response of the models. The TMR-200 small multichannel dynamic data acquisition instrument was used to measure the strain data of the models.

2.6. Test Methods. In this paper, El Centro wave (NS direction) $[29,30]$ was inputted along the east-west direction, and the seismic wave inputted into the shaking table was compressed to 0.1414 times of the original wave according to the time-similarity ratio. The peaks acceleration used for prototype seismic waves was 7 degrees $(0.1 \mathrm{~g}), 8$ degrees $(0.2 \mathrm{~g})$, 8 degrees $(0.3 \mathrm{~g})$, and 9 degrees $(0.4 \mathrm{~g})[31,32]$, respectively. According to the similarity ratio, the seismic wave peaks in the actual input model were adjusted to $0.25 \mathrm{~g}, 0.375 \mathrm{~g}, 0.5 \mathrm{~g}$, $0.75 \mathrm{~g}$, and $1 \mathrm{~g}$, respectively. The two model structures were loaded one-by-one and level-by-level on the shaking table. The load conditions 1-5 were applied with seismic model and the load conditions 6-10 were applied with isolation model.

Table 3 shows the theoretical and measured peak acceleration values of the shaking table under different load conditions in the model structure test. Thus it can be seen that the input intensity of seismic wave on the shaking table can meet the requirements.

\section{Analysis and Study on Experimental Phenomena}

3.1. Experimental Phenomena of Seismic Model. The damage to seismic model under seismic excitation was mainly in the form of cracks in piers, as shown in Figure 6. When 


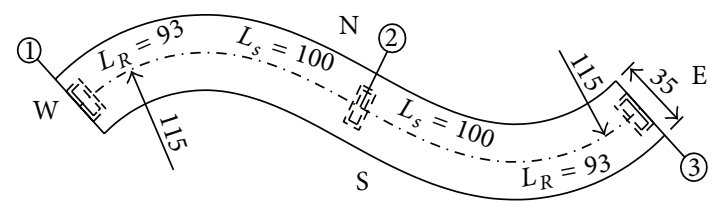

(a) Plan view

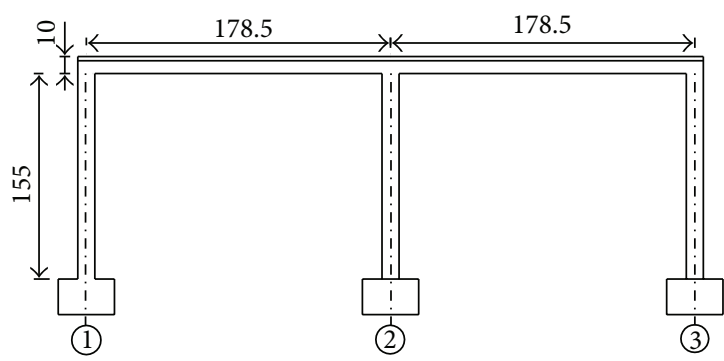

(b) Elevation of seismic model

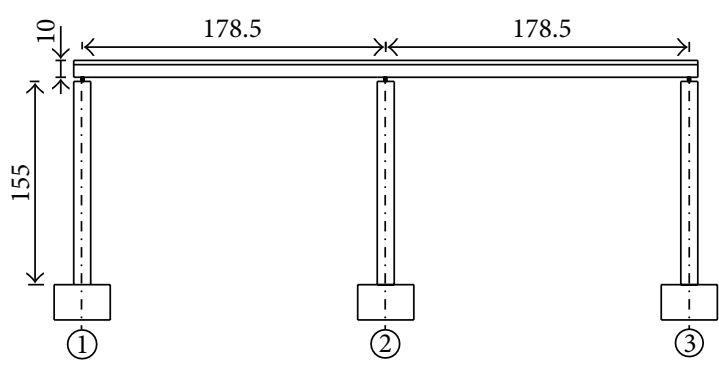

(c) Elevation of isolation model

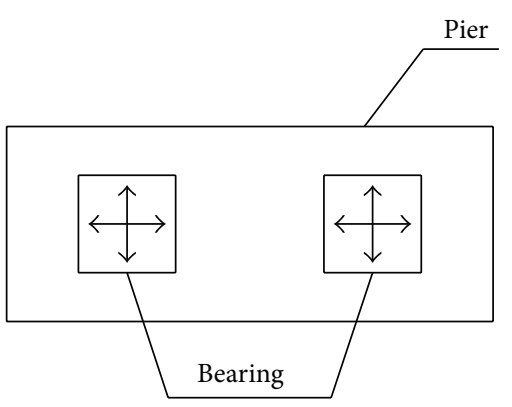

(d) Bearing arrangement

Figure 3: Design of model (unit: $\mathrm{cm}$ ).

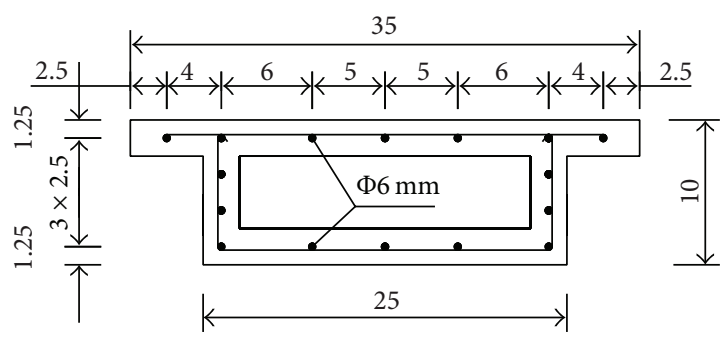

(a) Girder

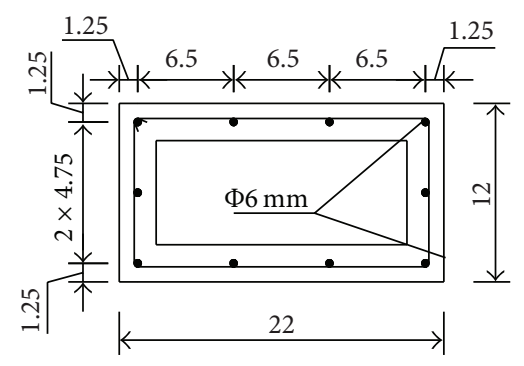

(b) Pier

FIGURE 4: Reinforcement assembly of section (unit: $\mathrm{cm}$ ).

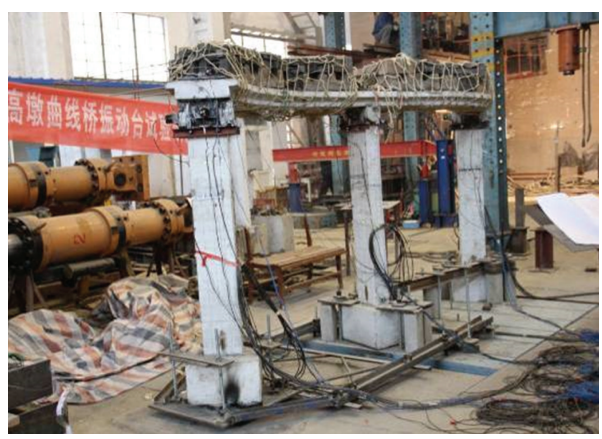

(a) Seismic model

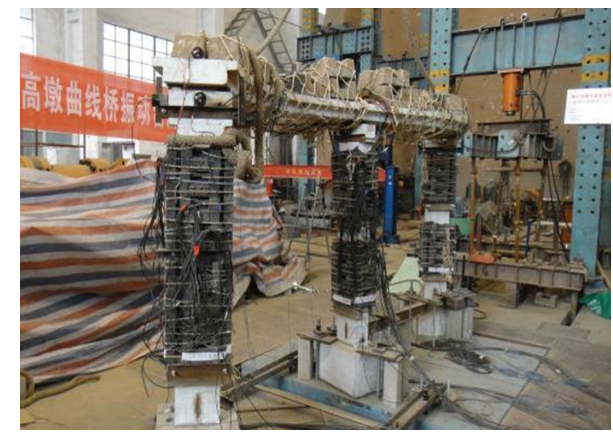

(b) Isolation model

Figure 5: Model weights.

the seismic wave was applied with $0.375 \mathrm{~g}$ PGA, a horizontal crack appeared firstly on the east side of bottom of pier \#1; the cracks of pier \#1 were distributed mainly near the bottom and the top of the pier, and the cracks were mostly horizontal bending cracks. When the seismic wave was applied with
0.25 g PGA, a horizontal curving crack appeared firstly on the west side of bottom of pier \#2; the cracks of pier \#2 were also distributed mainly nearby the bottom and the top of the pier, but horizontal and diagonal cracks were also found in the pier. When the seismic wave was applied with $0.375 \mathrm{~g}$ PGA, 

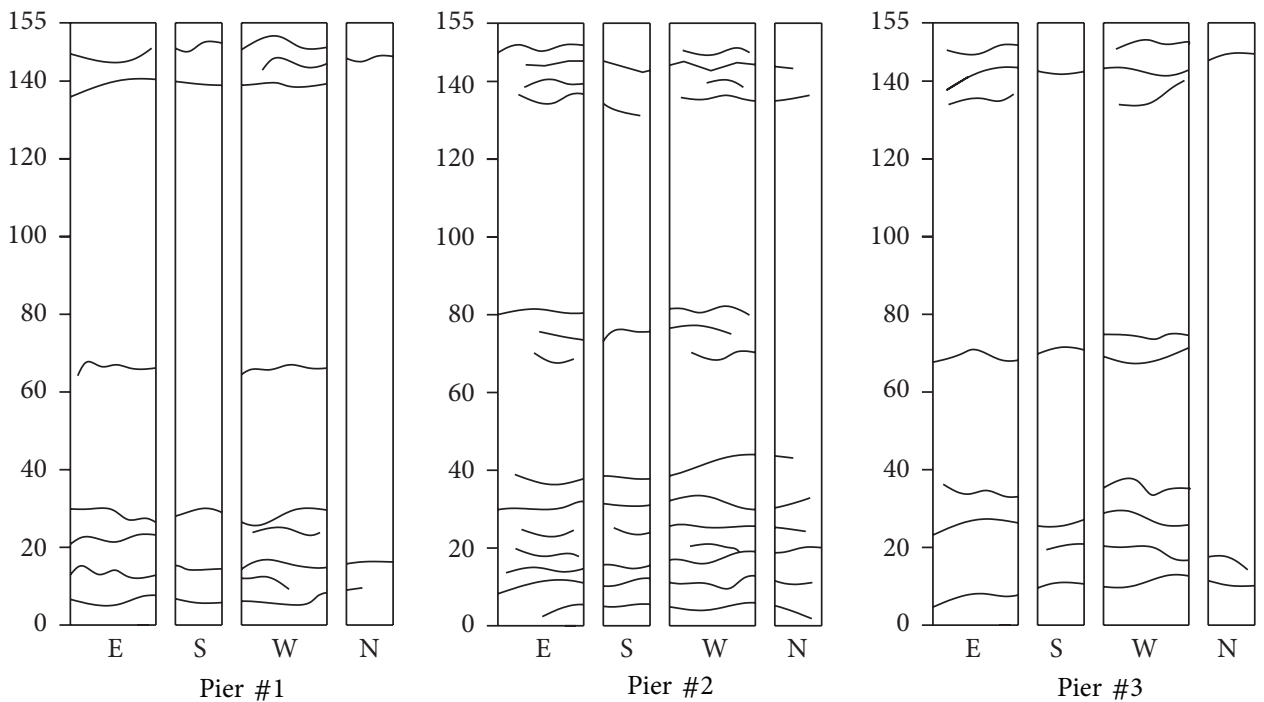

Figure 6: Pier's crack distribution (unit: $\mathrm{cm}$ ).

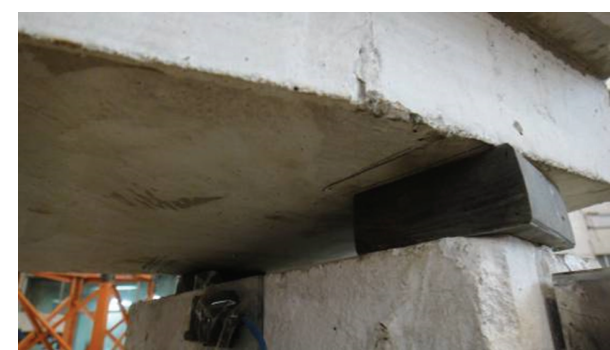

(a) Bearing sliding

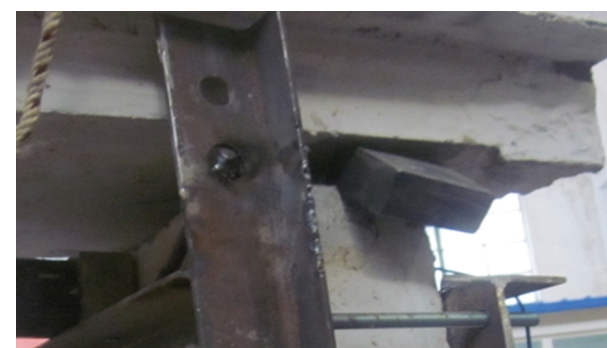

(b) Bearing coming off

FIGURE 7: Damage to bearings.

a horizontal bending crack appeared firstly on the east side of bottom of pier \#3; the cracks of pier \#3 were also distributed mainly at the bottom and the top of the pier. During the test, the length and width of cracks in each pier gradually became larger with the increase of seismic intensity.

\subsection{Experimental Phenomena of Isolation Model. The isola-} tion model suffers less damage to its piers than the seismic model. The bearings were placed directly on the piers without any treatment throughout the test. When the seismic wave was applied with $0.375 \mathrm{~g}$ PGA, the outer arc side bearing of pier \#1 was found with radial sliding in sliding distance of $3 \mathrm{~mm}$; the outer arc side bearing of pier \#3 was found sliding along both tangential and radial directions of the bridge, including tangential sliding of $2 \mathrm{~mm}$ and radial sliding of $2 \mathrm{~mm}$. When the seismic wave was applied with $0.5 \mathrm{~g}$ PGA, the outer arc side bearings of piers \#1 and \#3 were found with sliding of $6 \mathrm{~mm}$ and $7 \mathrm{~mm}$ in addition to the original sliding; the inner arc side bearing of pier \#1 was in radial sliding of $2 \mathrm{~mm}$ and tangential sliding of $3 \mathrm{~mm}$; the inner arc side bearing of pier \#3 was in radial sliding of $2 \mathrm{~mm}$ and tangential sliding of $4 \mathrm{~mm}$. When the seismic wave was applied with $0.75 \mathrm{~g}$ PGA, the outer arc side bearing of pier \#1 partially came off the girder, and all the remainder bearings have greater sliding. When the seismic wave was applied with $1 \mathrm{~g}$ PGA, the outer arc side bearing of pier \#1 completely came off; the bearing on the north side of pier 2\# came off the girder by $1 / 2$; the bearing on the outer arc side of pier \#3 came off the girder by $2 / 3$. The typical seismic damage to the bearings was shown in Figure 7.

Conclusion can be drawn from the above experimental phenomena:

(1) The main seismic damage to the seismic model is exhibited as the many cracks due to excessive force at the bottom of pier and the pier-girder connections. Compared with the seismic model, bearings in isolation bridge are placed directly between girder and pier; the bearings in the isolation model slide significantly upon completion of the test and even slide out of the pier top.

(2) The contact surfaces of the curved bridge with consideration of bearing friction sliding isolation may have certain slide under seismic excitation. The seismic horizontal forces are transmitted only through friction action of the contact surfaces. Not only will the 
bearing friction consume part of the seismic energy, but it also will play the role of reducing the effect of transferring the inertia force of the superstructure to the substructure under seismic excitation. Therefore, the dynamic response of the isolation bridge is effectively reduced. Throughout the test, the damage to the isolation model pier is relatively smaller. Thus, the curved bridge with seismic design considering bearing friction sliding isolation has proven to have good seismic performance and can be applied to seismic design of high-intensity earthquake area.

\section{Analysis of Test Results}

4.1. Analysis of Dynamic Characteristics. In order to obtain the dynamic characteristics at different stages of the model bridge, the fundamental frequency of each model was tested by hammering before and after the load conditions were applied to each test, while the damping ratio corresponding to the fundamental frequency of the structure was obtained by using the logarithmic decrement method in dynamics of structures [33] in order to reflect the stiffness degradation of the model bridges throughout the test. The dynamic characteristics of the model before and after loading under different conditions are shown in Table 4.

Table 3 shows that the isolation model bearing has relatively smaller shear stiffness; thus the isolation model has smaller initial fundamental frequency compared to that of the seismic structure. With the gradual increase in the inputting seismic intensity, the fundamental frequency of the model structure decreases, while the damping ratio increases. Upon analysis, it is known that the fundamental frequency decrease following the severe structural stiffness degradation of model is mainly caused by the cracks of piers for seismic model; the stiffness of the isolation model was impaired and the fundamental frequency decreased mainly due to the significant sliding of laminated rubber bearings in the earthquake and the consequent changes in boundary conditions.

With the increase of seismic intensity, the damping ratio of the model increases. When the seismic wave was applied with $1 \mathrm{~g}$ PGA, the damping of the seismic model increases to be $475 \%$ compared to the original damping ration; and the damping of the isolation model increases to be $636 \%$ compared to the original damping ration. Increase of structural damping makes the structure have better capacity of seismic energy dissipation. Change law of damping ration and frequency of isolation bridge indicate better seismic capacity when isolation bridge is in injured working state.

4.2. Analysis of Acceleration Response. Table 5 shows the acceleration response peak values of the corresponding measuring points on the top and bottom of piers on the seismic model bridge and isolation model bridge under different intensity levels of El Centro wave. The isolation effects of the model bridges can be reflected through analyzing these values.
TABLE 4: Dynamic characteristics of the model.

\begin{tabular}{lcccc}
\hline $\begin{array}{l}\text { Acceleration } \\
\text { amplitude (g) }\end{array}$ & \multicolumn{2}{c}{ Seismic model } & \multicolumn{2}{c}{ Isolation model } \\
Frequency & $\begin{array}{c}\text { Damping } \\
\text { (HZ) }\end{array}$ & $\begin{array}{c}\text { ratio (\%) } \\
\text { (HZ) }\end{array}$ & $\begin{array}{c}\text { Damping } \\
\text { ratio (\%) }\end{array}$ \\
\hline 0 & 5.675 & 3.64 & 5.078 & 2.79 \\
0.25 & 4.697 & 4.04 & 3.951 & 4.19 \\
0.375 & 4.305 & 4.47 & 3.315 & 7.04 \\
0.5 & 4.011 & 7.94 & 3.204 & 9.30 \\
0.75 & 2.739 & 14.37 & 2.703 & 11.83 \\
1 & 2.642 & 20.93 & 2.116 & 20.52 \\
\hline
\end{tabular}

The following can be seen from Table 5:

(1) For seismic models, the peak acceleration values at the corresponding positions of the piers top were all magnified compared with the bottom of pier as the effect of acceleration along the height direction of bridge pier is magnified.

(2) With the increase in seismic intensity, the bearings of the isolation model start to slide above the pier, and the sliding of bearings reduced the transfer of seismic inertia force of the girder towards the piers, thereby playing effective isolation action. Under load condition 7 , the tangential peak acceleration value at the top of pier \#2 was reduced to $17.7 \%$ compared with the bottom of pier. Under load condition 8 , the tangential peak acceleration value at the top of pier \#2 was reduced to $23.2 \%$ compared with the bottom of pier, and the tangential peak acceleration value at the top of \#3 pier is reduced to $11.8 \%$ compared with the bottom of pier. Under load condition 9, the peak acceleration value at the top of pier \#2 was reduced to $15.4 \%$ compared with the bottom of pier, the radial peak acceleration value at the top of pier \#3 is reduced to $7.6 \%$ compared with the bottom of pier, and the tangential peak acceleration value at the top of pier \#3 was reduced to $24.6 \%$ compared with the bottom of pier. Under load condition 10, the radial peak acceleration value at the top of pier \#3 was reduced to $14.3 \%$ compared with the bottom of pier.

Figure 8 shows the comparison chart of pier top acceleration time history curves of seismic model and isolation model.

The following can be seen from Figure 8:

(1) The peak acceleration values on top of the piers of the isolation model were reduced to varying degree under earthquake excitation of different seismic intensities compared with the seismic model.

(2) When the input peak acceleration of seismic wave was $0.25 \mathrm{~g}$ PGA, the reduction rates of tangential peak acceleration at the top of piers $\# 1, \# 2$, and $\# 3$ are $28.5 \%$, $42.6 \%$, and $32.2 \%$, respectively, and the reduction rate of radial peak acceleration at the top of pier \#3 is 7.8\%.

(3) When the input peak acceleration of seismic wave was $0.375 \mathrm{~g}$ PGA, the reduction rates of tangential peak 


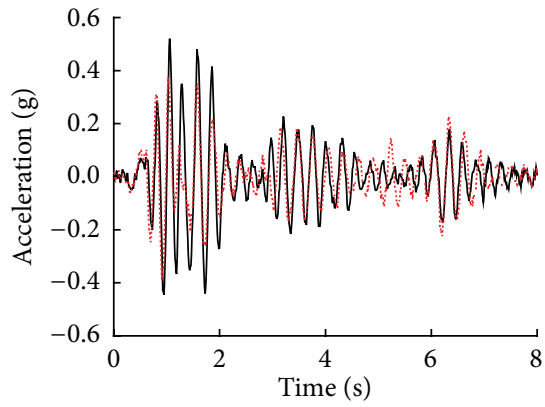

$\begin{array}{ll}\text { —.... Seismic model } & \text { Isolation model }\end{array}$

(a) $0.25-1-\mathrm{T}$

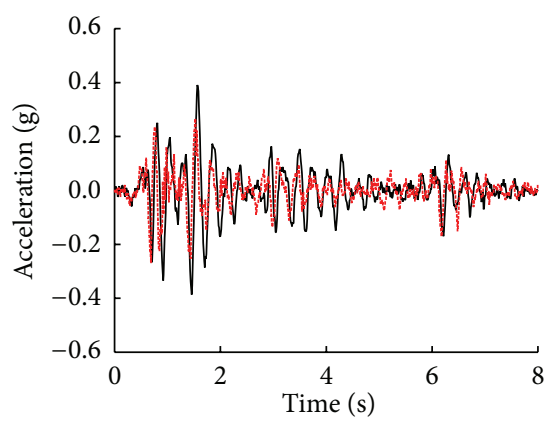

— Seismic model

Isolation mode

(d) $0.25-3-\mathrm{T}$

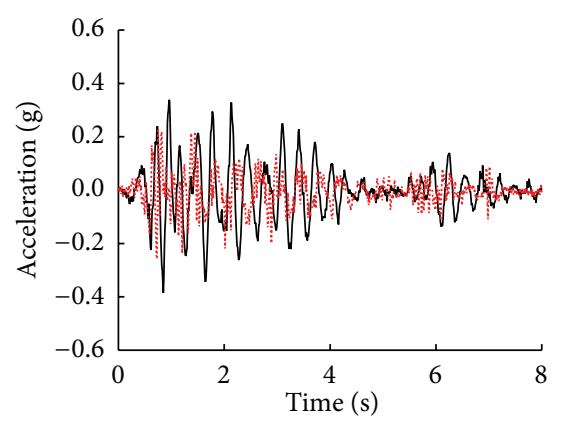

_- Seismic model

..... Isolation model

(g) $0.375-3-\mathrm{R}$

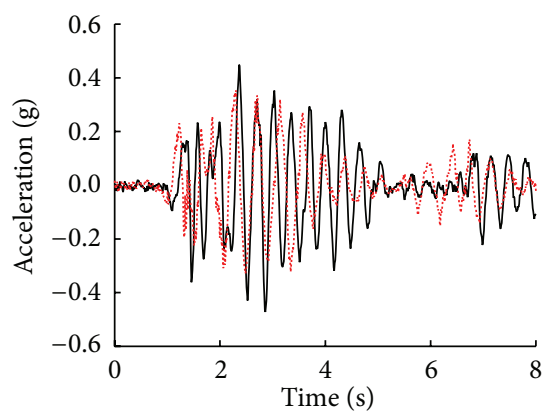

$\begin{array}{ll}- & \text { Seismic model } \\ \ldots . . . & \text { Isolation model }\end{array}$

(j) $0.5-2-\mathrm{T}$

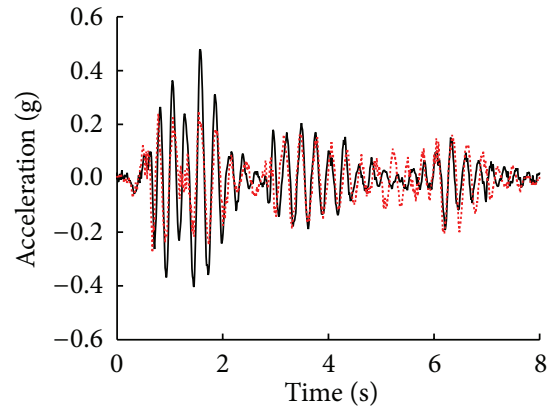

__ Seismic model

Isolation model

(b) $0.25-2-\mathrm{T}$

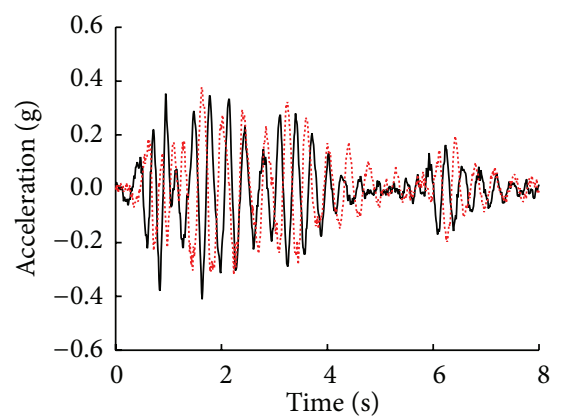

_- Seismic model

Isolation model

(e) $0.375-1-\mathrm{T}$

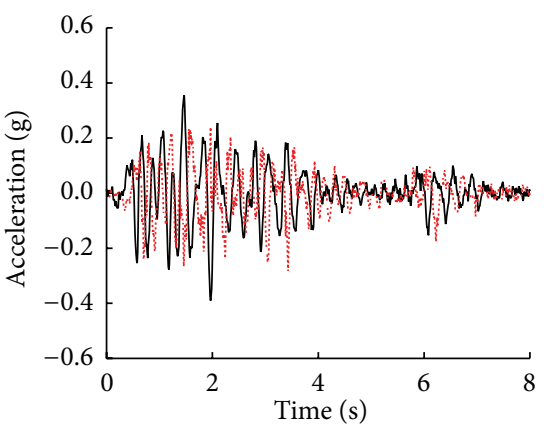

__ Seismic model

..... Isolation model

(h) $0.375-3-\mathrm{T}$

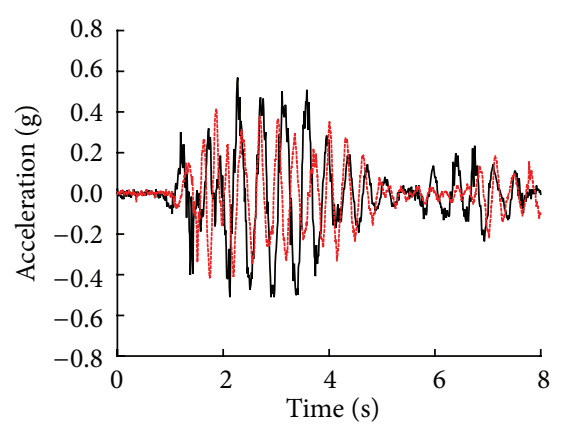

$\begin{array}{ll}\text { - Seismic model } \\ \text {.... } & \text { Isolation model }\end{array}$

(k) $0.5-3-\mathrm{R}$

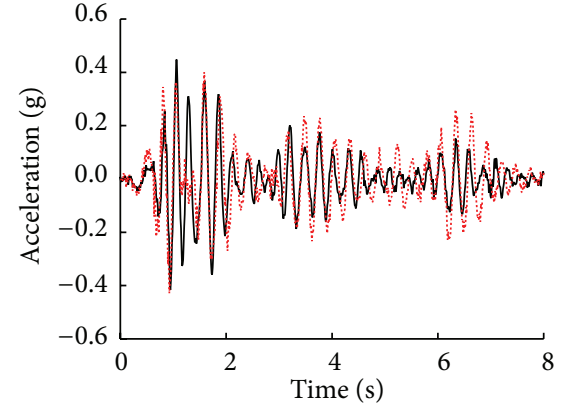

_ Seismic model

Isolation model

(c) $0.25-3-\mathrm{R}$

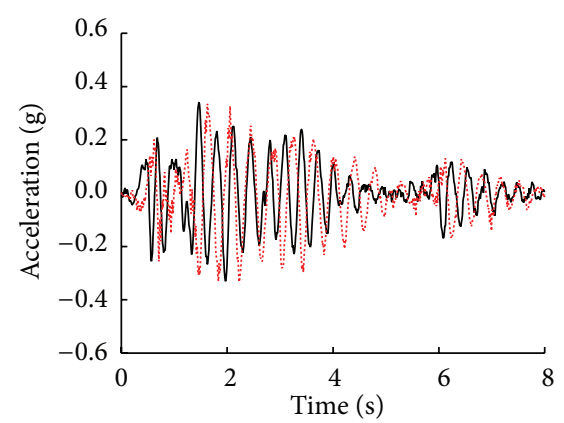

__ Seismic model

Isolation model

(f) $0.375-2-\mathrm{T}$

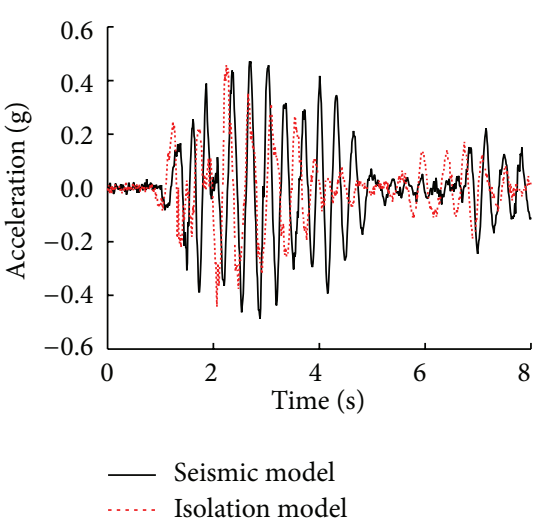

(i) $0.5-1-\mathrm{T}$

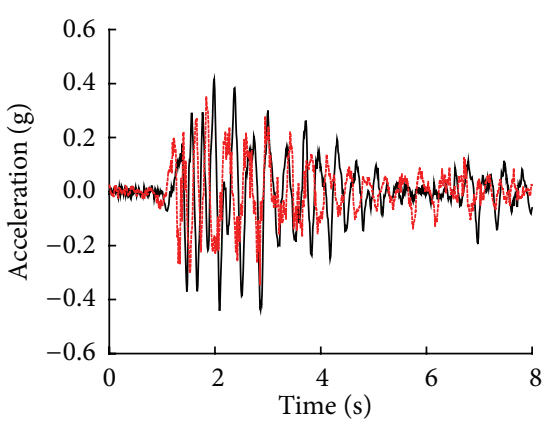

- Seismic model Isolation model

Figure 8: Continued. 


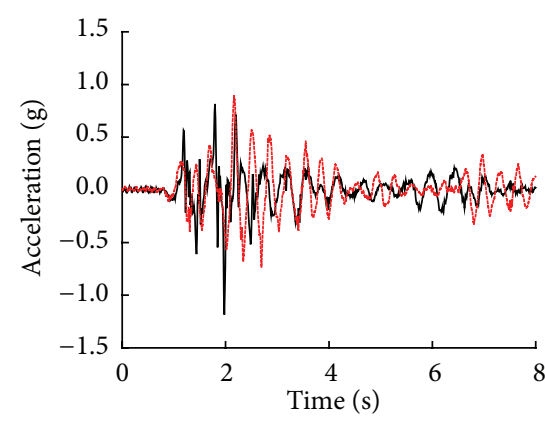

- Seismic model

...... Isolation model

(m) $0.75-1-\mathrm{T}$

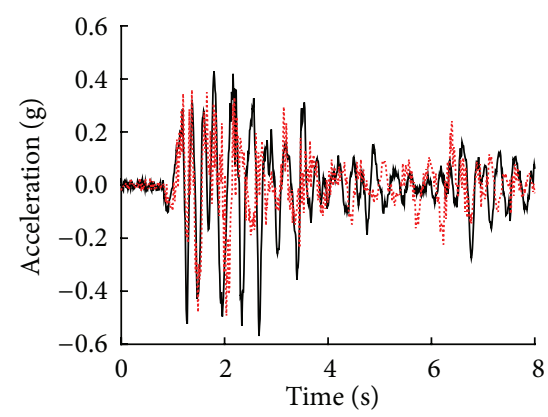

- Seismic model
..... Isolation model

(p) $0.75-3-\mathrm{T}$

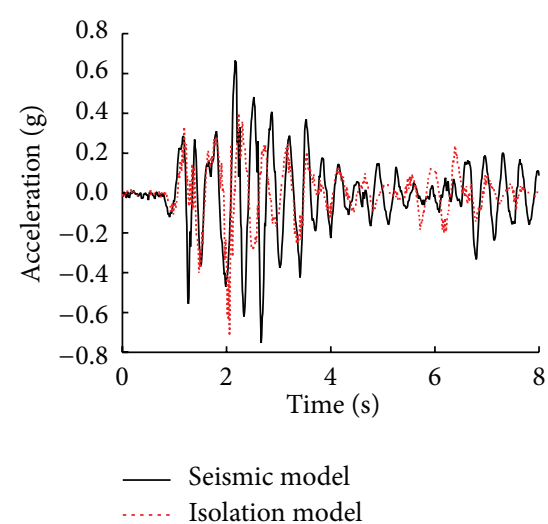

(n) $0.75-2-\mathrm{T}$

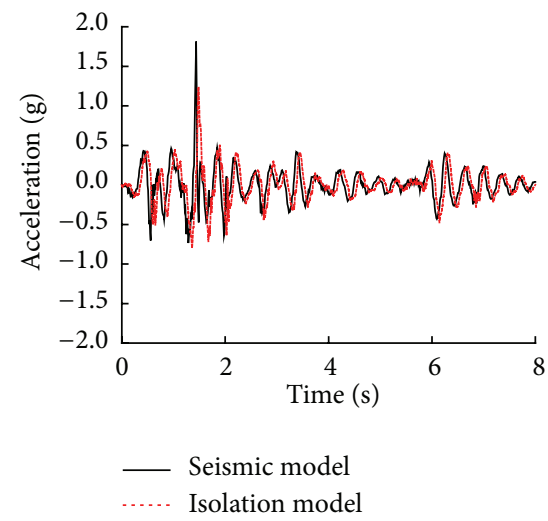

(q) 1-1-T

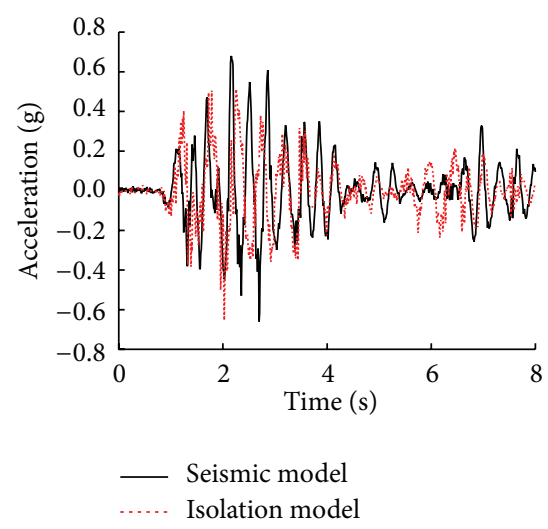

(o) $0.75-1-\mathrm{R}$

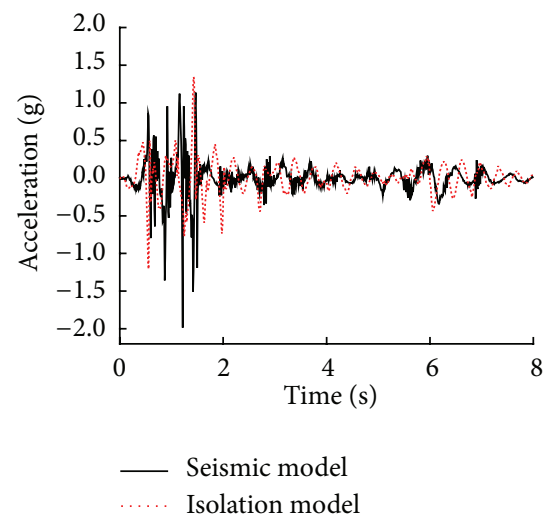

(r) 1-2-T

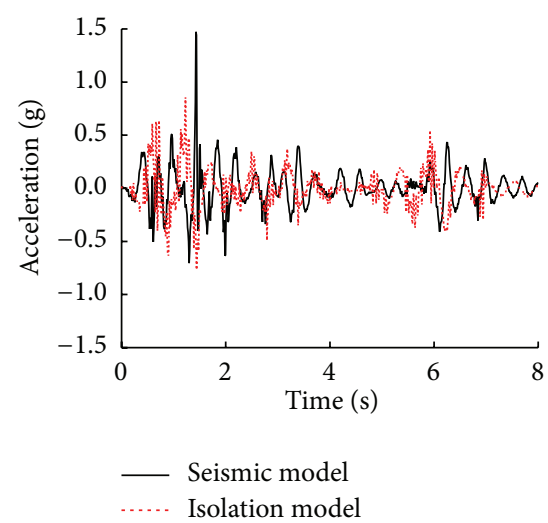

(s) $1-3-R$

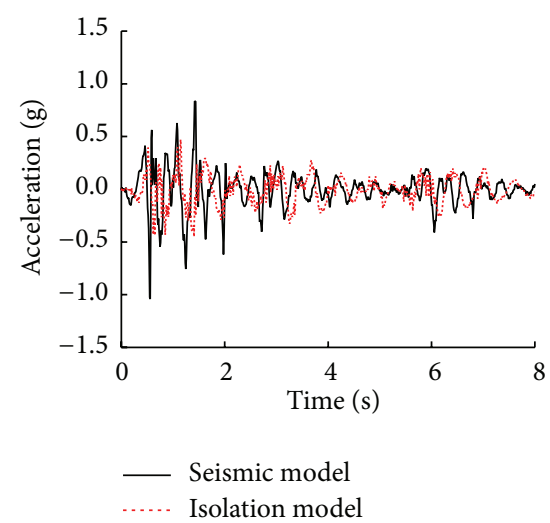

(t) $1-3-\mathrm{T}$

FIGURE 8: Comparison of time history curves of acceleration. Note: $0.25-1-\mathrm{R}$ stands for the radial acceleration time history curves of the top of pier \#1 when the input peak acceleration of seismic wave was $0.25 \mathrm{~g}$ PGA; 0.25-1-T stands for the tangential acceleration time history curves of the top of pier \#1 when the input peak acceleration of seismic wave was $0.25 \mathrm{~g}$ PGA and similar to other circumstances.

acceleration at the top of piers \#1, \#2, and \#3 are $10.6 \%$, $3.7 \%$, and $30.4 \%$, respectively, and the reduction rate of radial peak acceleration at the top of pier \#3 is $23.2 \%$.

(4) When the input peak acceleration of seismic wave was $0.5 \mathrm{~g}$ PGA, the reduction rates of tangential peak acceleration at the top of piers $\# 1, \# 2$, and $\# 3$ are $6.7 \%$, $21.4 \%$, and $28.7 \%$, respectively, and the reduction rate of radial peak acceleration at the top of pier \#3 is $30.1 \%$.

(5) When the input peak acceleration of seismic wave was $0.75 \mathrm{~g}$ PGA, the reduction rates of tangential peak acceleration at the top of piers \#1, \#2, and \#3 are $27.2 \%$, $11.1 \%$, and $26.9 \%$, respectively, and the reduction rate of radial peak acceleration at the top of pier \#3 is $8.5 \%$. 
TABLE 5: Peak acceleration of measuring points (unit: g).

\begin{tabular}{|c|c|c|c|c|c|c|c|c|c|c|c|}
\hline \multirow{2}{*}{\multicolumn{2}{|c|}{ Measuring point }} & \multicolumn{10}{|c|}{ Load condition } \\
\hline & & $\begin{array}{c}1 \\
\mathrm{SM}\end{array}$ & $\begin{array}{c}6 \\
\mathrm{IM}\end{array}$ & $\begin{array}{c}2 \\
\mathrm{SM}\end{array}$ & $\begin{array}{c}7 \\
\mathrm{IM}\end{array}$ & $\begin{array}{c}3 \\
\mathrm{SM}\end{array}$ & $\begin{array}{c}8 \\
\mathrm{IM}\end{array}$ & $\begin{array}{c}4 \\
\mathrm{SM} \\
\end{array}$ & $\begin{array}{c}9 \\
\mathrm{IM}\end{array}$ & $\begin{array}{c}5 \\
\text { SM }\end{array}$ & $\begin{array}{c}10 \\
\mathrm{IM} \\
\end{array}$ \\
\hline Bottom of pier \#1 & \multirow{2}{*}{ Tangential } & 0256 & 0242 & 0379 & 0310 & 0307 & 0460 & 0764 & 0.694 & 0800 & 0062 \\
\hline Top of pier \#1 & & 0.520 & 0.372 & 0.415 & 0.371 & 0.486 & 0.453 & 1.243 & 0.905 & 1872 & 1623 \\
\hline Bottom of pier \#2 & \multirow{2}{*}{ Tangential } & 0.210 & 0.262 & 0.341 & 0.413 & 0.440 & 0.483 & 0.612 & 0.790 & 0.867 & 1.133 \\
\hline Top of pier \#2 & & 0.479 & 0.275 & 0.353 & 0.340 & 0.472 & 0.371 & 0.753 & 0.669 & 1.986 & 1.345 \\
\hline Bottom of pier \#3 & \multirow{2}{*}{ Radial } & 0.128 & 0.175 & 0.205 & 0.277 & 0.284 & 0.352 & 0.452 & 0.654 & 0.598 & 0.906 \\
\hline Top of pier \#3 & & 0.446 & 0.411 & 0.501 & 0.385 & 0.594 & 0.415 & 0.660 & 0.604 & 1.473 & 0.776 \\
\hline Bottom of pier \#3 & \multirow{2}{*}{ Tangential } & 0.206 & 0.198 & 0.241 & 0.275 & 0.311 & 0.357 & 0.490 & 0.552 & 0.713 & 0.395 \\
\hline Top of pier \#3 & & 0.391 & 0.265 & 0.391 & 0.272 & 0.442 & 0.315 & 0.569 & 0.416 & 1.041 & 0.463 \\
\hline
\end{tabular}

Note: SM stands for the seismic model; IM stands for the isolation model.

(6) When the input peak acceleration of seismic wave was $1 \mathrm{~g}$ PGA, the reduction rates of tangential peak acceleration at the top of piers $\# 1, \# 2$, and $\# 3$ are $13.3 \%$, $32.3 \%$, and $55.5 \%$, respectively, and the reduction rate of radial peak acceleration at 3\# pier top was $47.3 \%$.

From the above analysis, when curved bridge design considering the bearings friction sliding isolation is used, the isolation effects become more remarkable with the increase in seismic intensity; the maximum reduction rates of peak acceleration can be up to $47.3 \%$ radially and $55.5 \%$ tangentially. The experimental results by Zhong et al. [23] which used longitudinal energy dissipation damper show that the maximum reduction rate of peak acceleration at the top of piers is $60 \%$. Liu et al. [24] conducted an experiment which used FPS, LRB, and high damping rubber bearings, respectively, and the maximum reduction rates of peak acceleration at the top of piers are $76 \%, 70 \%$, and $56 \%$, respectively. Compared with the experimental results of other researchers, the maximum reduction rate is $55.5 \%$.

4.3. Analysis of Displacement Response. Previous study results show that the displacement of the superstructure above the isolation layer will be amplified, which exists in the isolation structures. The displacement time history curve in this paper shows the comparison of the top of pier \#2 and its upper girder under effect of El Centro wave at different seismic intensities, as shown in Figure 9.

Figure 9 shows that the tangential displacement of girder in the isolation model was essentially consistent with that of the pier, but the radial displacement of the girder in relation to the pier top was considerably increased. With the increase of seismic intensity, the radial displacement of the girder significantly increased compared with the pier. When the input peak acceleration of seismic wave was $1 \mathrm{~g}$, the radial relative displacement between girder and pier top is up to $13.7 \mathrm{~mm}$.

The experimental results of previous studies $[23,24]$ and this paper have proved that the design of the bridge with isolation device can lead the displacement of girders to be amplified. Therefore, how to control the radial displacement value of the girder within reasonable limit is an important issue that must be considered in isolation design of curved bridge so as to strictly prevent damage, for example, radial pounding between the girder and the retainer and radial girder unseating. Currently, measures, for example, the addition of seismic retainers or damping devices, can be adopted to minimize the displacement of the bridge superstructure.

4.4. Analysis of Strain Response. The destruction due to excessive force carried by the bridge pier is one of the main forms of seismic damage which occurred to curved bridge during earthquake $[34,35]$; therefore the strains at the bottom of pier of the model curved bridge were studied in this paper. Figure 10 shows the strain time history curves at the bottom of piers for seismic and isolation models at different seismic intensities.

The following can be seen from Figure 10:

(1) When the input peak acceleration of seismic wave was applied from $0.25 \mathrm{~g}$ to $1 \mathrm{~g}$, the strain peak values for the bottom of pier \#1 of seismic model were $205 \mu \varepsilon, 358 \mu \varepsilon, 445 \mu \varepsilon, 846 \mu \varepsilon$, and $1013 \mu \varepsilon$, respectively, and the peak values for the bottom of pier \#1 of isolation model were $168 \mu \varepsilon, 339 \mu \varepsilon, 416 \mu \varepsilon, 563 \mu \varepsilon$, and $582 \mu \varepsilon$, respectively, and the peak reduction rates were $18 \%, 5.3 \%, 6.5 \%, 33.5 \%$, and $42.5 \%$, respectively; the strain peak values for the bottom of pier $\# 2$ of seismic model were $483 \mu \varepsilon, 490 \mu \varepsilon, 612 \mu \varepsilon, 969 \mu \varepsilon$, and $1234 \mu \varepsilon$, respectively, the strain peak values for the bottom of pier $\# 2$ of isolation model were $298 \mu \varepsilon$, $456 \mu \varepsilon, 513 \mu \varepsilon, 894 \mu \varepsilon$, and $798 \mu \varepsilon$, respectively, and the peak reduction rates were $38.3 \%, 6.9 \%, 16.2 \%$, $19.1 \%$, and $43.4 \%$ respectively; the strain peak values for the bottom of pier \#3 of seismic model were $176 \mu \varepsilon$, $369 \mu \varepsilon, 418 \mu \varepsilon, 797 \mu \varepsilon$, and $859 \mu \varepsilon$, respectively, the strain peak values for the bottom of pier \#3 of seismic model were $164 \mu \varepsilon, 232 \mu \varepsilon, 310 \mu \varepsilon, 525 \mu \varepsilon$, and $503 \mu \varepsilon$, respectively, and the peak reduction rates were $6.8 \%$, $37.1 \%, 25.8 \%, 34.1 \%$, and $41.4 \%$, respectively.

(2) In summary, the peak strain values for the bottom of piers of the isolation model are greatly reduced compared with the seismic model. Basically, the isolation effect increases proportionally with the seismic intensity. The curved bridge considering bearing 


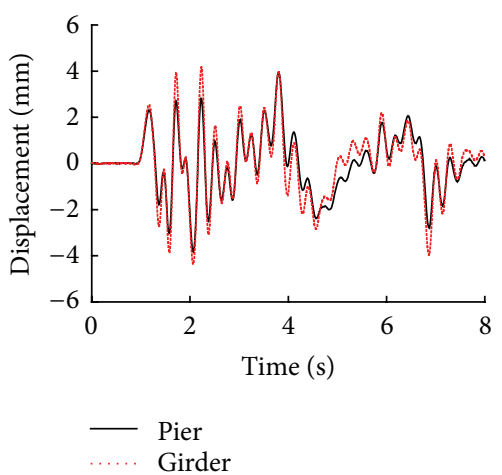

(a) $0.25-\mathrm{R}$

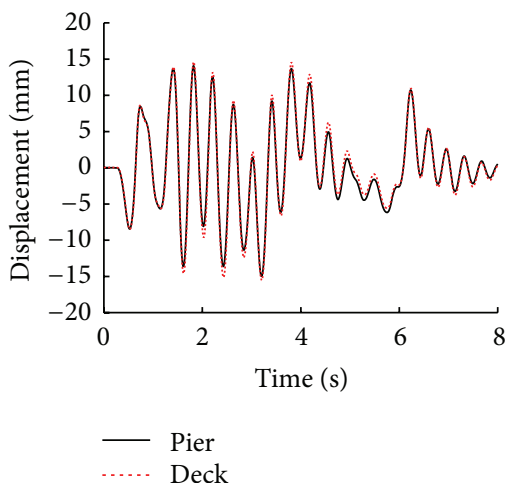

(d) $0.375-\mathrm{T}$

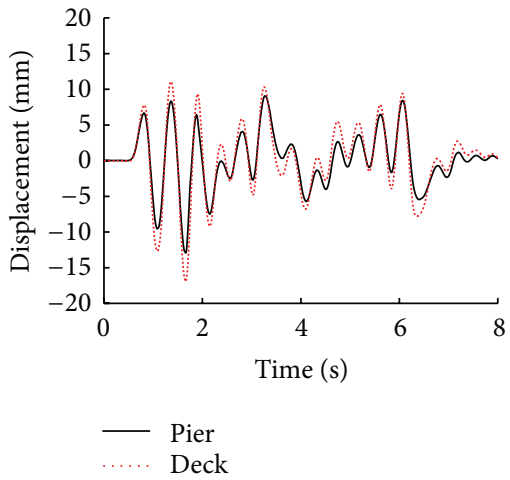

(g) $0.75-\mathrm{R}$

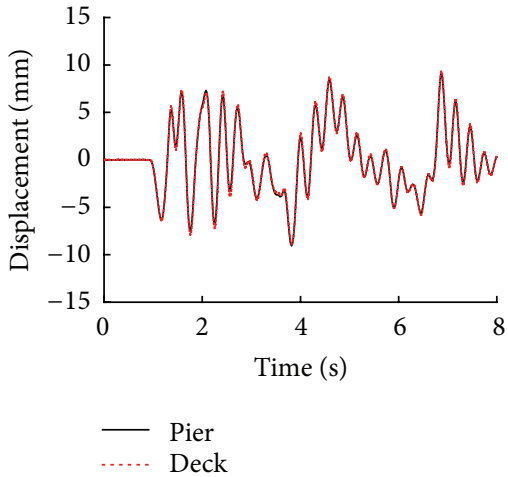

(b) $0.25-\mathrm{T}$

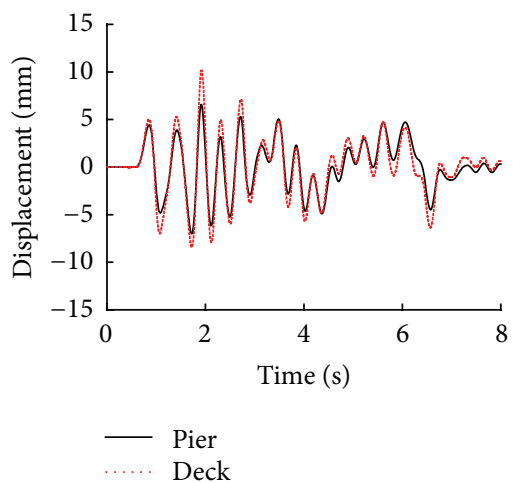

(e) $0.5-R$

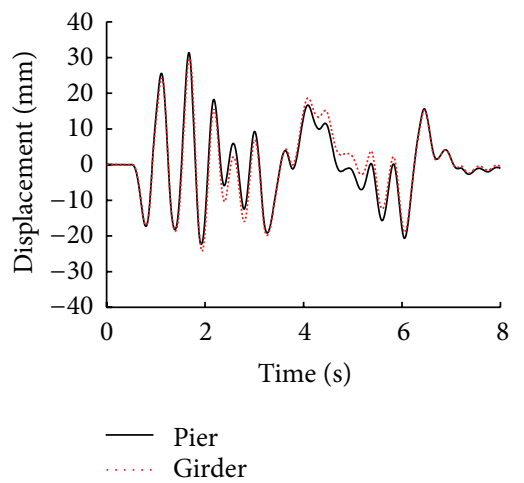

(h) $0.75-\mathrm{T}$

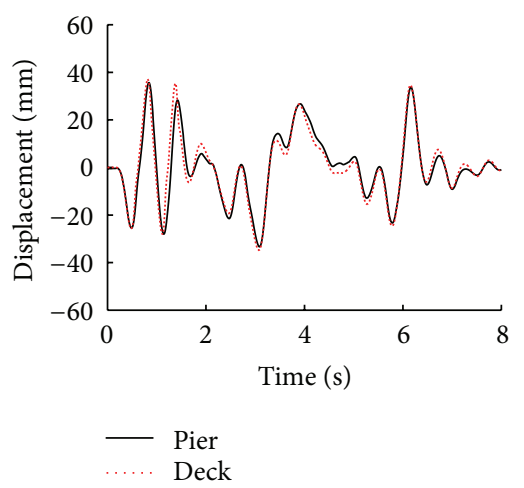

(j) $1-\mathrm{T}$

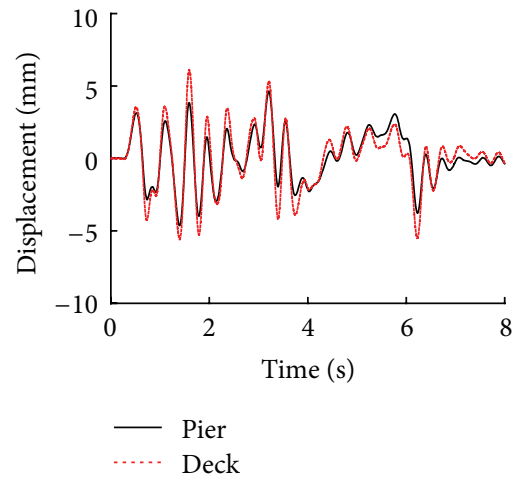

(c) $0.375-\mathrm{R}$

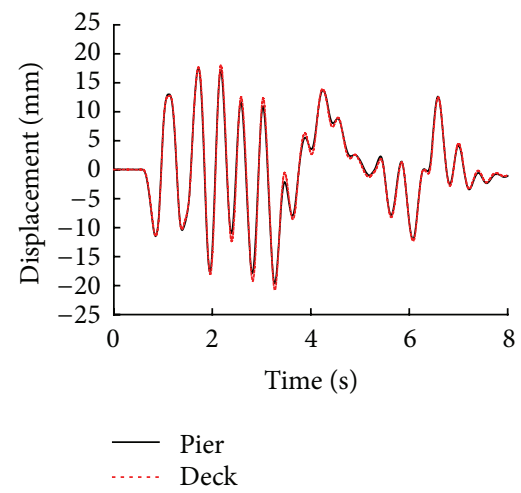

(f) $0.5-\mathrm{T}$

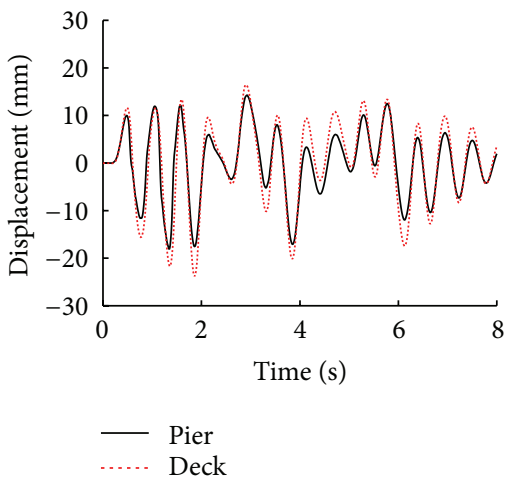

(i) $1-\mathrm{R}$

FIGURE 9: Comparison of time history curve of displacement. Note: $0.25-\mathrm{R}$ stands for the radial displacement time history curves of pier top and girder when the input peak acceleration of seismic wave was $0.25 \mathrm{~g}$ PGA; 0.25 -T stands for the tangential displacement time history curves of pier top and girder when the input peak acceleration of seismic wave was $0.25 \mathrm{~g}$ PGA and similar to other circumstances. 


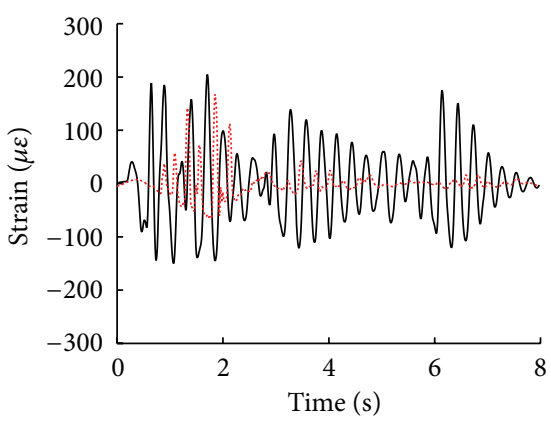

— Seismic model

Isolation model

(a) $0.25-1$

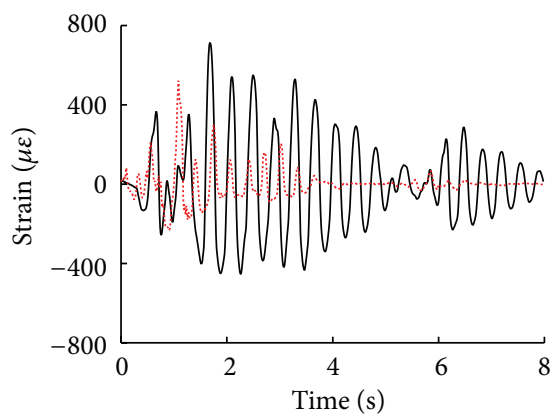

$\begin{array}{ll}\text { - Seismic model } \\ \text {..... } & \text { Isolation model }\end{array}$

(d) $0.375-1$

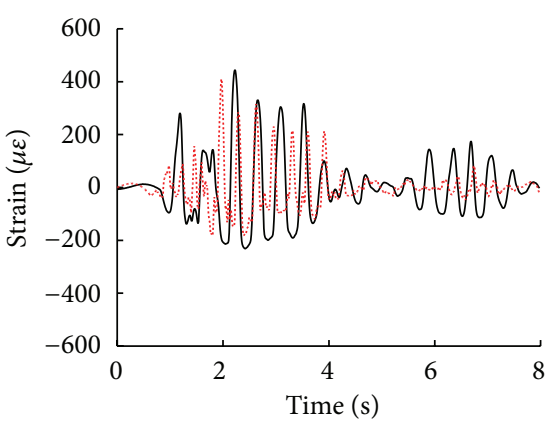

— Seismic model

Isolation model

(g) $0.5-1$

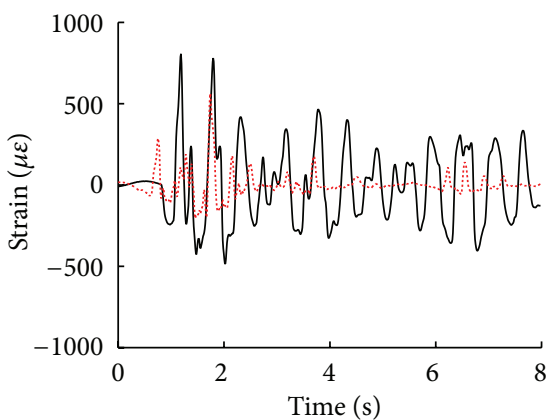

- Seismic model

Isolation model

(j) $0.75-1$

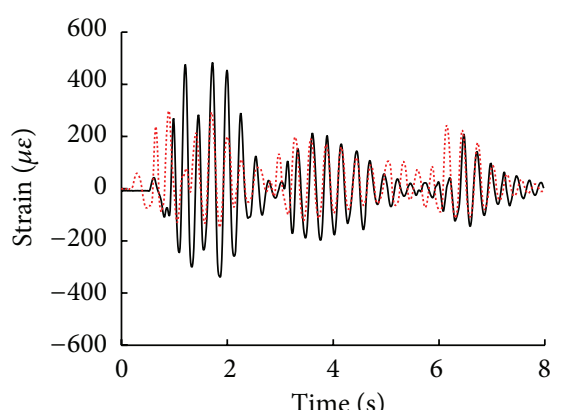

- Seismic model

solation model

(b) $0.25-2$

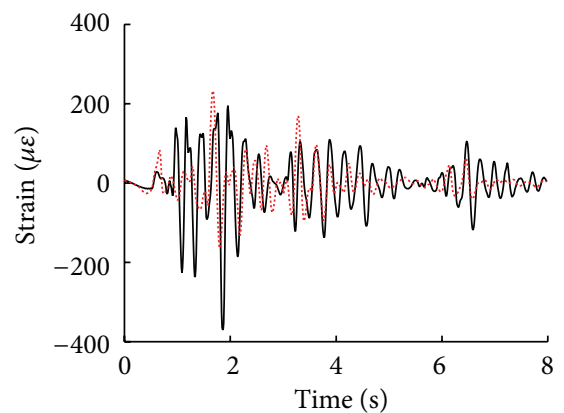

- Seismic model

Isolation model

(e) $0.375-2$

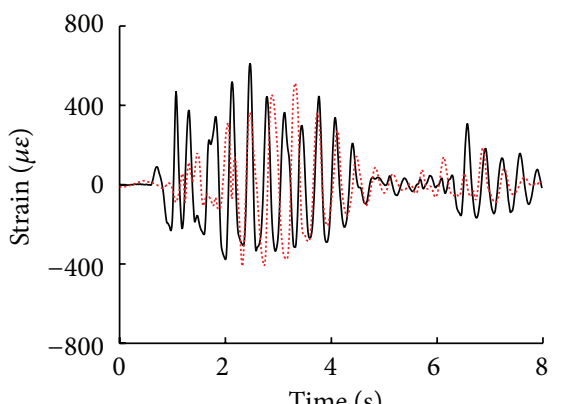

_ Seismic model

..... Isolation model

(h) $0.5-2$

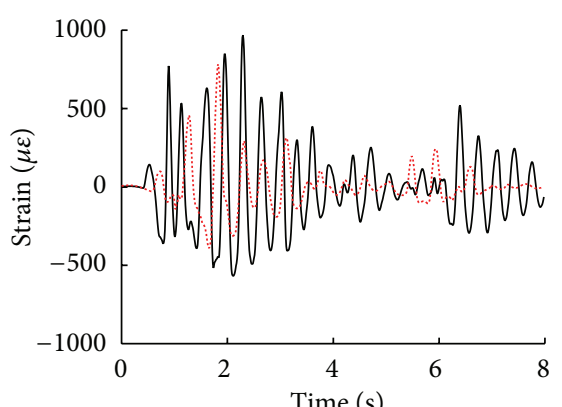

— Seismic model

(k) $0.75-2$

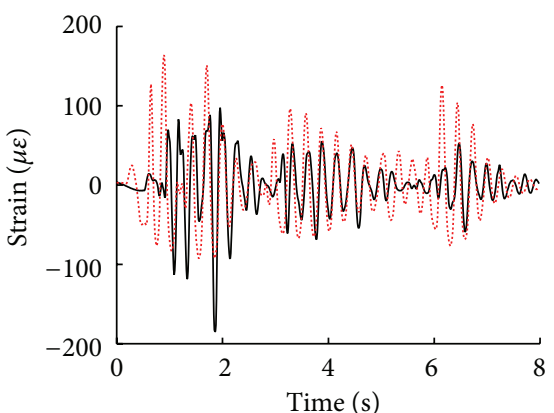

- Seismic model

Isolation model

(c) $0.25-3$

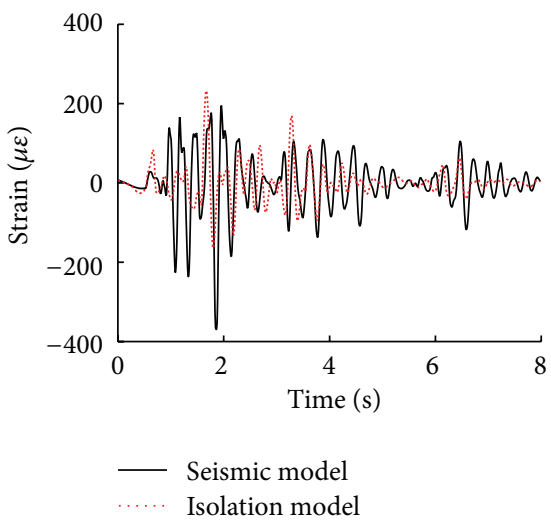

(f) $0.375-3$

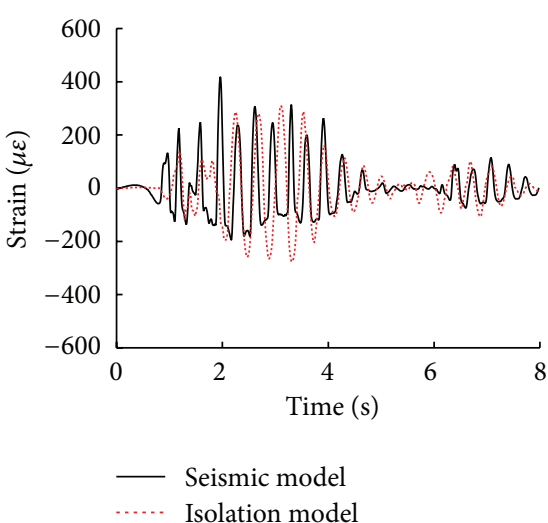

(i) $0.5-3$

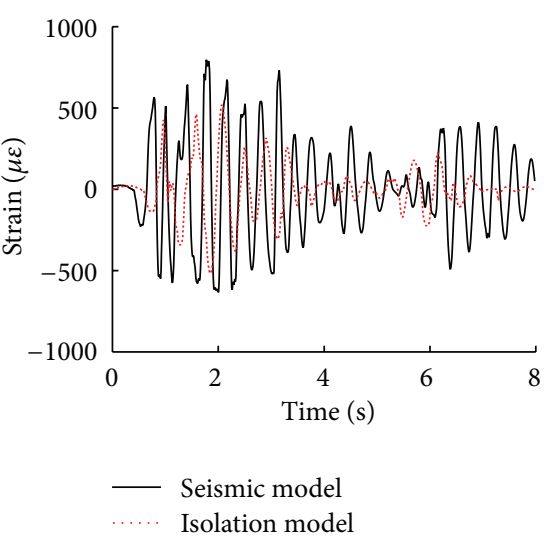

(l) $0.75-3$

Figure 10: Continued. 


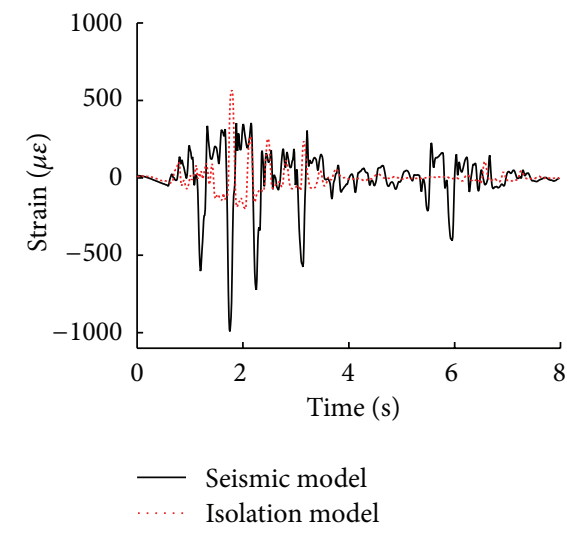

(m) $1-1$

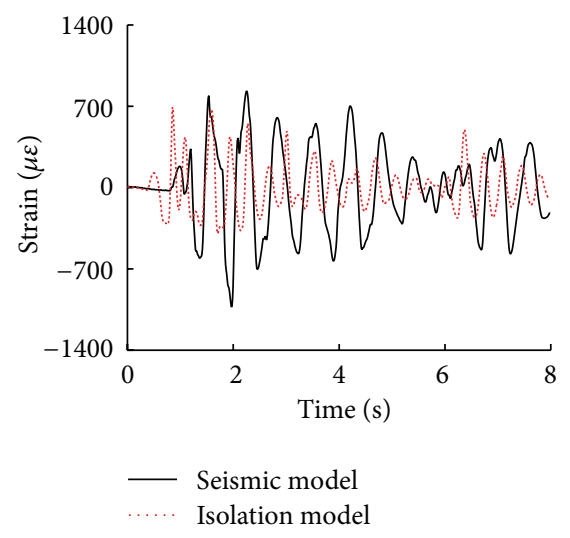

(n) $1-2$

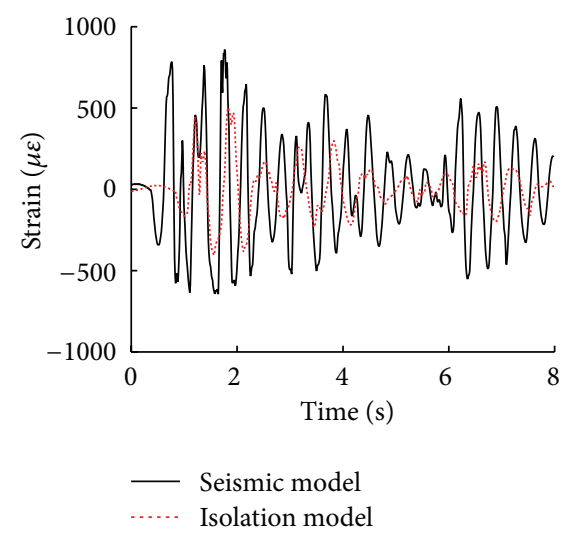

(o) $1-3$

FIGURE 10: Comparison of strain time history curves. Note: $0.25-1$ shows the strain time history curve at the bottom of pier \#1 when the input peak acceleration of seismic wave was $0.25 \mathrm{~g}$ PGA and similar to other circumstances.

friction sliding isolation is designed to isolate the girder from the lower part of the bridge structure using bearing, reasonably extend the life cycle of the bridge structure system, and reduce the seismic force transmitted from the bridge superstructure to the pier by dissipating partial seismic energy and avoid or reduce the nonelastic deformation of the bridge pier. The previous experiment result [23] reveals that the maximum reduction rate of peak strain at the bottom of piers can be up to $47 \%$; the maximum reduction rate in our paper is $41.4 \%$. Both the previous experiment result and the experiment result in our paper indicate that the isolation device can effectively reduce the strain response of the piers.

\section{Conclusions}

In this paper, the shaking table comparison tests of two curved bridges considering or not bearings friction sliding isolation are carried out, respectively; the dynamic characteristics and response of the model structures are studied. The following conclusions can be drawn:

(1) With the increase of seismic intensity, the natural frequencies of the two model bridges significantly decrease, while the damping ration increases. The stiffness is degraded for both the seismic model and the isolation model. The stiffness degradation of seismic model is caused by severe damage after cracks appear at piers, and the stiffness degradation of isolation model is caused by the change in boundary condition of bridge due to greater sliding movement of the bearings.

(2) For curved bridge considering bearing friction sliding isolation, its maximum reduction rate of peak acceleration at the pier top after earthquake is $24.6 \%$ compared with the bottom of pier. Its damping effect is more significant with the increase of seismic intensity in contrast to the curved bridge without considering bearing friction sliding isolation. The maximum reduction rate is $47.3 \%$ for radial peak acceleration and $55.5 \%$ for tangential peak acceleration.

(3) The tangential displacement response of the girder of the isolation curved bridge is basically not magnified compared with the pier, while the maximum radial relative displacement between girder and pier is $13.7 \mathrm{~mm}$. Thus, during seismic design, the radial displacement of the curved bridge should be strictly controlled, and the girder unseating damage can be avoided by measures, for example, the installation of energy-dissipated vibration reduction retainers.

(4) The strain values at the bottom of pier of the curved bridge without considering bearing friction sliding isolation become greater with the increase of seismic intensity. In contrast, the strain values on the bottom of pier of the curved bridge considering bearing friction sliding isolation decrease with increase of seismic intensity. Under the same intensity, the strain values at the bottom of pier of isolation model have significantly reduced compared with the seismic model, with maximum reduction rate of $43.4 \%$. Therefore, the curved bridge considering bearing friction sliding isolation has remarkable seismic effect, and it can be applied to the seismic design of high-intensity seismic areas.

(5) The curved bridge considering bearing friction sliding isolation adopts clear-cut isolation mechanism. Its friction sliding can be used to dissipate seismic energy under earthquake action and minimize the seismic force transferred to the substructure. In addition, the laminated rubber bearing has advantages of simple construction, low cost, and easy installation, so that the operational capability of bridge can be restored after earthquake through reinstatement or the replacement of the bearings. 


\section{Competing Interests}

The authors declare that there are no competing interests regarding the publication of this paper.

\section{Acknowledgments}

The research presented herein was supported by the Natural Science Foundation of China (Grant no. 51078306) and the Youth Foundation of China (Grant no. 51508453). The writers are grateful for this support.

\section{References}

[1] D. Williams and W. Godden, "Seismic response of long curvedbridge experimental model studies," Earthquake Engineering and Structural Dynamics, vol. 7, no. 2, pp. 107-128, 1979.

[2] J. Seo and D. G. Linzell, "Horizontally curved steel bridge seismic vulnerability assessment," Engineering Structures, vol. 34, no. 1, pp. 21-32, 2012.

[3] T. Wilson, H. Mahmoud, and S. Chen, "Seismic performance of skewed and curved reinforced concrete bridges in mountainous states," Engineering Structures, vol. 70, no. 3, pp. 158-167, 2014.

[4] K. Liu and L.-H. Wang, "Earthquake damage of curved highway bridges in 2008 Wenchuan earthquake," Advanced Materials Research, vol. 838-841, pp. 1571-1576, 2014.

[5] T. Yoshizawa, "Laminated rubber bearing for seismic isolation," Kobunshi, vol. 57, no. 7, p. 523, 2008.

[6] L.-C. Fan, L.-Y. Nie, and J.-Z. Li, "Dynamic characteristic analysis of laminated rubber bearing sliding under earthquake," China Journal of Highway and Transport, vol. 16, no. 4, pp. 3035, 2003 (Chinese).

[7] M. Abe, J. Yoshida, and Y. Fujino, "Multiaxial behaviors of laminated rubber bearings and their modeling. I: Experimental Study," Journal of Structural Engineering, vol. 130, no. 8, pp. 11191132, 2004.

[8] O. E. Ozbulut and S. Hurlebaus, "Seismic assessment of bridge structures isolated by a shape memory alloy/rubber-based isolation system," Smart Materials and Structures, vol. 20, no. 1, Article ID 015003, 2011.

[9] Y. Zhang, X. Hu, and S. Zhu, "Seismic performance of benchmark base-isolated bridges with superelastic $\mathrm{Cu}$-Al-Be restraining damping device," Structural Control and Health Monitoring, vol. 16, no. 6, pp. 668-685, 2009.

[10] L. Wang, W. M. Yan, and G. P. Yan, "Effect of the LRB parameters on the dynamic response of the isolationd bridges," Journal of Beijing University of Technology, vol. 30, no. 3, pp. 304-308, 2004.

[11] K. Wilde, P. Gardoni, and Y. Fujino, "Base isolation system with shape memory alloy device for elevated highway bridges," Engineering Structures, vol. 22, no. 3, pp. 222-229, 2000.

[12] M. A. R. Bhuiyan and M. S. Alam, "Seismic vulnerability assessment of a multi-span continuous highway bridge fitted with shape memory alloy bars and laminated rubber bearings," Earthquake Spectra, vol. 28, no. 4, pp. 1379-1404, 2012.

[13] C. P. Providakis, "Effect of supplemental damping on LRB and FPS seismic isolators under near-fault ground motions," Soil Dynamics and Earthquake Engineering, vol. 29, no. 1, pp. 80-90, 2009.

[14] S. Ates and M. C. Constantinou, "Example of application of response spectrum analysis for seismically isolated curved bridges including soil-foundation effects," Soil Dynamics and Earthquake Engineering, vol. 31, no. 4, pp. 648-661, 2011.

[15] S. Ates and M. C. Constantinou, "Example of application of response history analysis for seismically isolated curved bridges on drilled shaft with springs representing soil," Soil Dynamics and Earthquake Engineering, vol. 31, no. 3, pp. 334-350, 2011.

[16] Y. Liu, J. X. Qi, J. Y. Wang, and S. G. Chen, "Seismic mitigation analysis of viscous dampers for curved continuous girder bridge," Applied Mechanics and Materials, vol. 90-93, pp. 12301233, 2011.

[17] N. P. Kataria and R. S. Jangid, "Seismic protection of the horizontally curved bridge with semi-active variable stiffness damper and isolation system," Advances in Structural Engineering, vol. 19, no. 3, 2016.

[18] P. Tsopelas, M. C. Constantinou, S. Okamoto, S. Fujii, and D. Ozaki, "Experimental study of bridge seismic sliding isolation systems," Engineering Structures, vol. 18, no. 4, pp. 301-310, 1996.

[19] K. Endo, T. Okada, and S. Unjoh, "Shaking table tests of bridges isolated by sliding bearings," Journal of Japan Society of Civil Engineers A, vol. 63, no. 3, pp. 396-410, 2007.

[20] M.-H. Tsai, S.-Y. Wu, K.-C. Chang, and G. C. Lee, "Shaking table tests of a scaled bridge model with rolling-type seismic isolation bearings," Engineering Structures, vol. 29, no. 5, pp. 694-702, 2007.

[21] Q. Han, X. L. Du, J. B. Liu, and W. G. Liu, "Seismic response of isolated bridges with lrb under muldi-directional earthquakepart," Journal of Vibration and Shock, vol. 27, no. 9, pp. 59-65, 2008 (Chinese).

[22] X.-L. Du, Q. Han, and J.-B. Liu, "Seismic response of isolated bridges with LRB under muldi-directional earthquake-part (II) theoretical and comparative analysis," Journal of Vibration and Shock, vol. 27, no. 9, pp. 66-71, 2008 (Chinese).

[23] D. Q. Zhong, S. G. Wang, and W. Q. Liu, "Shaking table experimental study and theoretical analysis of the longitudinal seismic-reduced behavior of continuous-beam bridges," China Civil Engineering Journal, vol. 45, no. 11, pp. 147-165, 2012 (Chinese).

[24] Y.-H. Liu, P. Tan, F.-L. Zhou, H. Wenliuhan, and O. Mercan, "Shaking table test for seismic simulation of continuous isolation girder bridge with high piers," China Journal of Highway and Transport, vol. 28, no. 2, pp. 60-68, 2015 (Chinese).

[25] M. Z. Zhang, "Study on similitude laws for shaking table tests," Journal of Earthquake Engineering and Engineering Vibration, vol. 17, no. 2, pp. 57-58, 1997 (Chinese).

[26] Y. Zhou and X. L. Lv, Test Methods and Technique of Building Structure Vibration Table Model, Science Press, Beijing, China, 2012 (Chinese).

[27] B. Felekoglu, High performance micro concrete design [Ph.D. thesis], Dokuz Eylul University, Izmir, Turkey, 2009.

[28] D. Shen and X. Lü, "Experimental study on the mechanical property of microconcrete in model test," China Civil Engineering Journal, vol. 43, no. 10, pp. 14-21, 2010 (Chinese).

[29] N. Jayaram, T. Lin, and J. W. Baker, "A Computationally efficient ground-motion selection algorithm for matching a target response spectrum mean and variance," Earthquake Spectra, vol. 27, no. 3, pp. 797-815, 2011.

[30] J. W. Baker, "Conditional mean spectrum: tool for groundmotion selection," Journal of Structural Engineering, vol. 137, no. 3, pp. 322-331, 2011.

[31] China Communications Press, "Guidelines for seismic design of highway bridges," Tech. Rep. JTG/T B02-01-2008, China Communications Press, Beijing, China, 2008 (Chinese). 
[32] GB, "Code for seismic design of buildings," Tech. Rep. GB500112010, China Architecture and Building Press, Beijing, China, 2010 (Chinese).

[33] R. Clough and P. Joseph, Dynamics of Structures, McGraw-Hill, New York, NY, USA, 1993.

[34] W. F. Chen and L. Duan, Bridge Engineering Seismic Design, CRC Press, London, UK, 2003.

[35] L. C. Fan, Bridge Engineering Sesmic, Tongji University Press, Shanghai, China, 2001 (Chinese). 


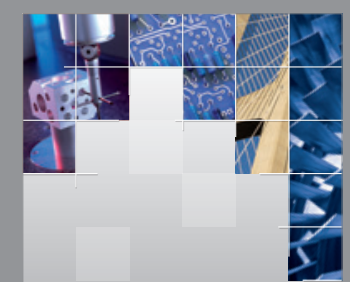

\section{Enfincering}
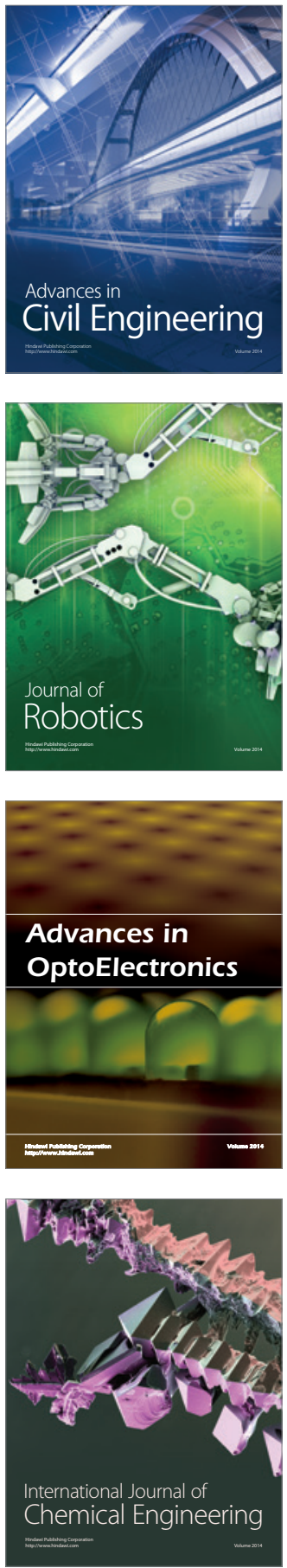

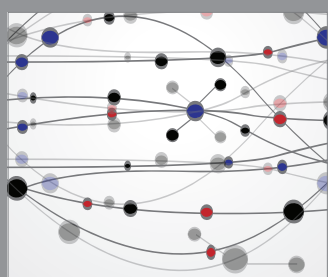

The Scientific World Journal

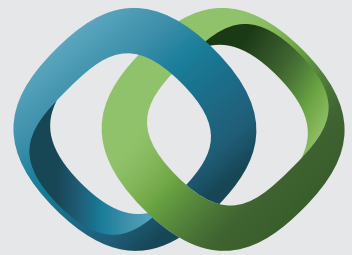

\section{Hindawi}

Submit your manuscripts at

http://www.hindawi.com
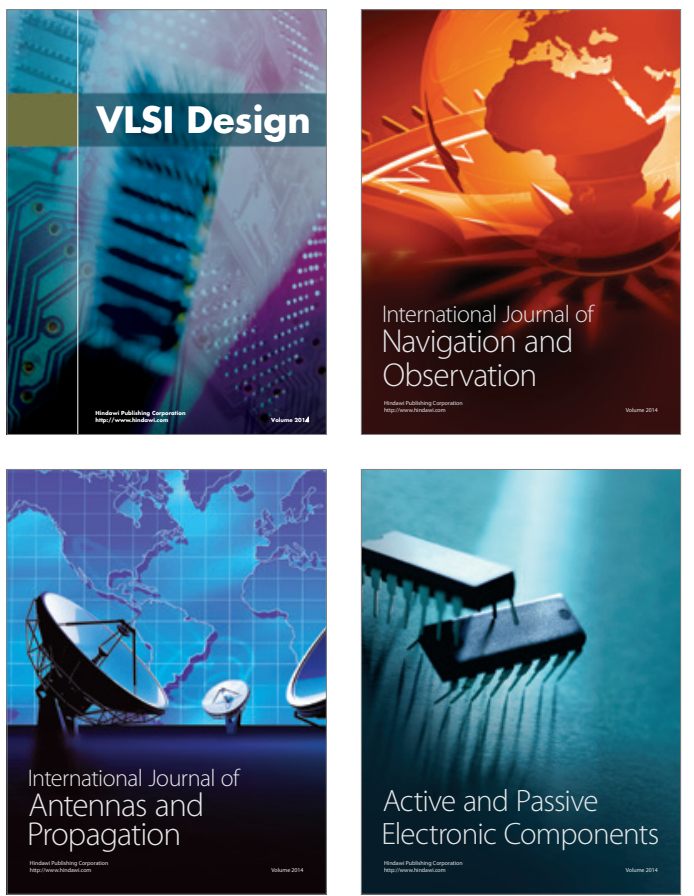
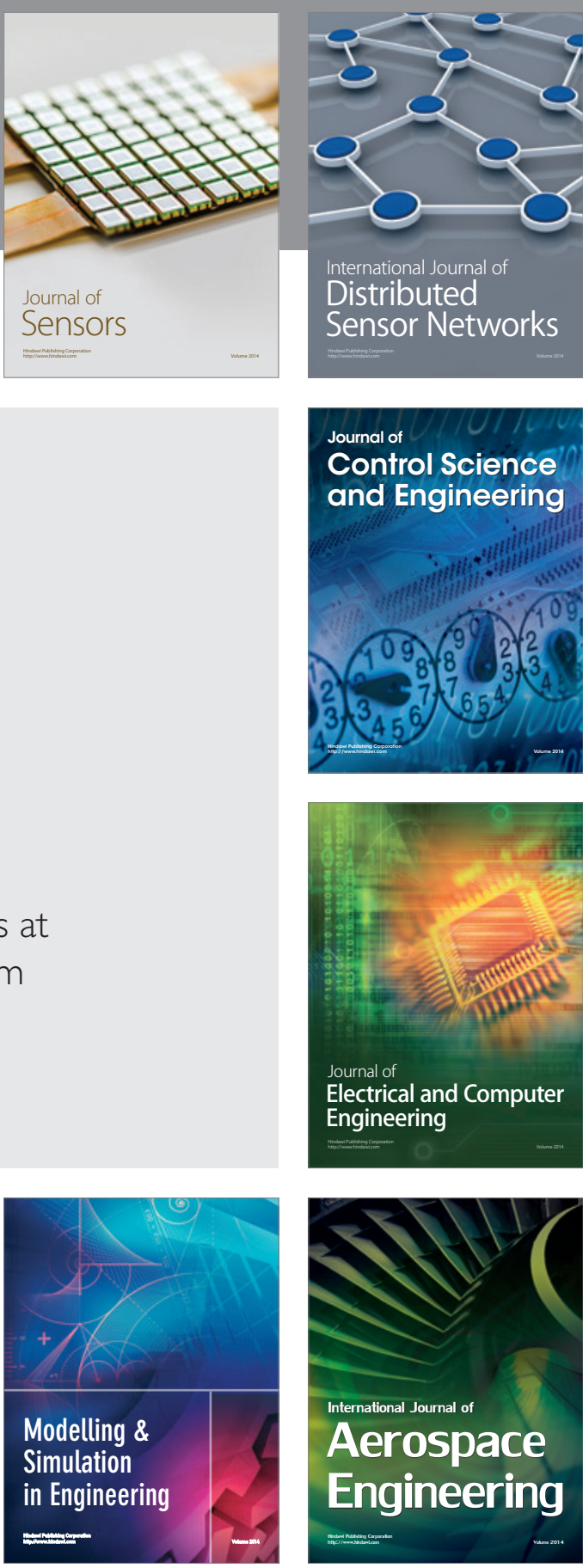

International Journal of

Distributed

Sensor Networks

Journal of

Control Science

and Engineering
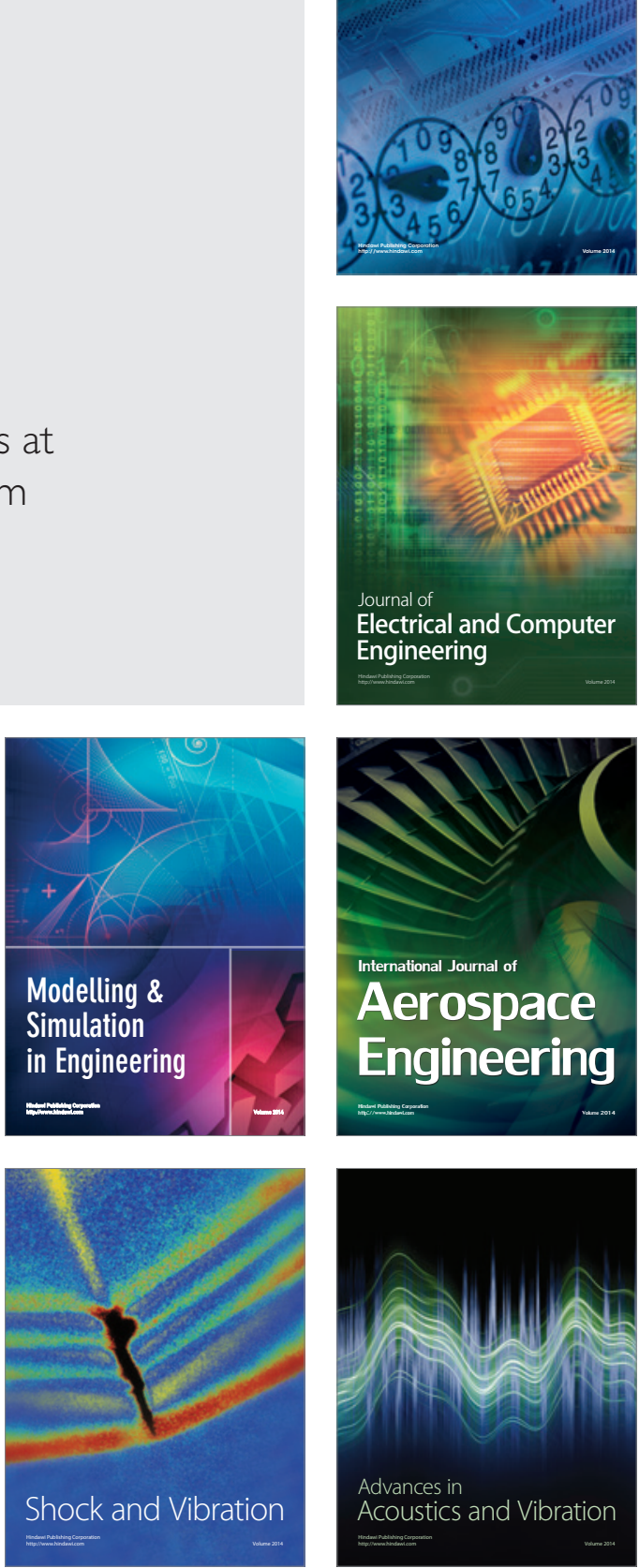